\title{
Administration of Anastrozole to Ovariectomized Rats Impairs Working Memory in Association with Plastic Changes to Dendritic Spines on Prefrontal Third-layer Pyramidal Neurons
}

\author{
Dulce A. Velázquez-Zamora ${ }^{1,2}$, Nestor I. Martínez-Torres ${ }^{2}$, Miguel Cervantes ${ }^{3}$ and Ignacio González-Burgos ${ }^{2^{*}}$ \\ ${ }^{1}$ Universidad Politécnica de la Zona Metropolitana de Guadalajara, Tlajomulco de Zúñiga, Jal., México \\ ${ }^{2}$ Laboratorio de Psicobiología, División de Neurociencias, Centro de Investigación Biomédica de Occidente, IMSS, Guadalajara, Jal., México \\ ${ }^{3}$ Laboratorio de Neurociencias, División de Estudios de Posgrado, Facultad de Ciencias Médicas y Biológicas "Dr lgnacio Chávez", UMSNH, Morelia, Mich., México
}

*Corresponding author: Ignacio González-Burgos PhD, Laboratorio de Psicobiología, División de Neurociencias, Centro de Investigación Biomédica de Occidente, Instituto Mexicano del Seguro Social, Sierra Mojada \#800, Col. Independencia, C.P. 44340 Guadalajara, Jal, México, Tel: +52 33 36683000-31950; Fax: +52 33 36181756; E-mail: igonbur@hotmail.com

Received date: June 02, 2016; Accepted date: July 19, 2016; Published date: July 23, 2016

Copyright: (c) 2016 Velázquez-Zamora DA, et al. This is an open-access article distributed under the terms of the Creative Commons Attribution License, which permits unrestricted use, distribution, and reproduction in any medium, provided the original author and source are credited.

\begin{abstract}
Gonadal estrogens influence several neurobiological events related to synaptic plasticity underlying cognitive behavior. Likewise, estradiol synthesized in neurons affects aspects of brain organization associated with cognition. Here, plastic changes to dendritic spines on third-layer pyramidal neurons from the prefrontal cortex of ovariectomized, anastrozole-treated female rats were studied. Anastrozole treatment dampened the efficiency of rats in resolving a spatial working memory test in the " $Y$ " maze when compared with ovariectomized control and proestrus female rats. In addition, the administration of Anastrozole led to an increase in dendritic spines and filopodia on the pyramidal cells studied. The thin, mushroom, stubby and wide spines remained unchanged. Since filopodia are considered to be the precursors of novel spines, the increase in dendritic spines is consistent with the increase in filopodia. However, this was clearly insufficient to drive proper working memory performance, despite the apparent stability in the translation of synaptic information suggested by the similar spine types evident in the ovariectomized controls and the increases observed. These findings show that brain-derived estradiol is necessary for prefrontal activity to account for working memory performance. Further studies will be needed to elucidate the mechanisms underlying such spine enhancement in the absence of estradiol-mediated modulation of plasticity.
\end{abstract}

Keywords: Anastrozole; Estrogen; Dendritic spines; Plasticity; Working memory; Prefrontal cortex

\section{Introduction}

Estrogens, mainly $17 \beta$ estradiol (E2), have recognized trophic and regulatory roles on the cytoarchitecture, connectivity and function of brain structures. Their activity not only influences events related to sexual behavior and reproductive in adult females but also, neural structures and processes that support other important brain activities like neuroprotection, or learning and memory [1-4]. These effects on neural tissue may be exerted by estrogens synthesized in the ovary, although E2 synthesized in several cerebral structures may also account for some estrogenic actions in the brain $[1,5,6]$. Thus, both endocrine and paracrine pathways supplying E2 may be involved in its regulatory activity in specific neural structures.

The pathway of steroidogenesis that ends in the synthesis of testosterone is active in neural and glial populations within specific brain structures, driving its metabolic conversion to $5 \alpha$ dihydrotestosterone by $5 a$-reductase or to estradiol through the activity of aromatase. Thus, it is likely that these "neurosteroids" can modify neural structure and function in these domains [7-12]. Indeed, testosterone aromatase activity has been shown to drive E2 synthesis in both the hippocampus and the prefrontal cortex of male and female rats, even in the absence of gonadal steroidogenesis [13-16]. These brain structures are mainly involved in different modalities of cognition in the brain and therefore, the estrogenic activity exerted by the E2 produced through ovarian and/or brain steroid synthesis can modify the structural and biochemical neural substrates of cognitive functions [17-20]. Cytoarchitectonic characteristics can be modified by estrogen-related phenomena, including: changes in dendritic spine density and in the proportion of the different spine types on the dendritic branches of pyramidal neurons; synaptic connectivity, activity and strength in hippocampal and prefrontal cortex neuronal circuits. Thus, hippocampal- and prefrontal cortex-dependent cognitive functions are likely to be susceptible to variations in E2 concentration and activity $[17,21,22]$.

Indeed, there is experimental evidence that supports an important role of the estrogen E2 synthesized through testosterone aromatization in these brain structures and its involvement in cognitive functions. Accordingly, inhibition of brain aromatase activity provokes structural and functional alterations to the neural substrate involved in hippocampal- and prefrontal cortex-dependent cognitive functions, leading to deficient performance of both experimental animals and humans in modality-specific learning/memory tests [19,23-30].

In the light of these findings, this study was designed to evaluate the effect of inhibiting aromatase activity in ovariectomized rats. Specifically, the effect on dendritic spine density and on the relative proportions of the different spine types was evaluated in pyramidal neurons located in the layer III of the prefrontal cortex. These changes were correlated with the performance of the experimental animals in an allocentric working memory test. 
Citation: Velázquez-Zamora DA, Martínez-Torres NI, Cervantes M, González-Burgos I (2016) Administration of Anastrozole to Ovariectomized Rats Impairs Working Memory in Association with Plastic Changes to Dendritic Spines on Prefrontal Third-layer Pyramidal Neurons. J Steroids Horm Sci 7: 179. doi:10.4172/2157-7536.1000179

Page 2 of 7

\section{Materials and Methods}

\section{Subjects}

Female Sprague-Dawley rats $(\mathrm{n}=48)$ weighing 250-300 gm were used in this study. The rats were housed at $25^{\circ} \mathrm{C}$ under a regular $12 / 12$ $\mathrm{h}$ light/dark cycle, and with ad libitum access to water and food, and they were verified to complete three regular estrous cycles lasting 5 days.

\section{Experimental design}

The animals were assigned to one of four study groups: 1) a control group of bilaterally ovariectomized rats (Ovx; $n=12) ; 2$ ) another control group of bilaterally ovariectomized rats to which $1 \mathrm{ml}$ of dimethylsulfoxide (DMSO) diluted $3 \%$ in saline solution was administered intraperitoneally (i.p., Ovx+Veh; $n=12$ ); 3) a further control group of rats studied in the proestrus stage $(14: 00 \mathrm{~h})$ of their estrous cycle (Proestrus; $\mathrm{n}=12$ ); and 4) an experimental group of bilaterally ovariectomized rats i.p. administered $1 \mathrm{mg} / \mathrm{kg}$ of Anastrozole [31,32] in $20 \mathrm{mg} / \mathrm{ml}$ DMSO diluted to $3 \%$ in saline solution $(\mathrm{Ovx}+\mathrm{Ans} ; \mathrm{n}=12)$. The ovariectomized rats were first anesthetized with ketamine $(60 \mathrm{mg} / \mathrm{kg}$, i.m.) followed by $25 \mathrm{mg} / \mathrm{kg}$ of sodium pentobarbital (i.p.). The pharmacological treatments to the Ovx, Ovx+Veh and Ovx+Ans rats were applied on day 6 after ovariectomy.

From the first-to-seventh day after ovariectomy, the animals were all handled daily for 15 minutes in order to minimize the effects of stress. Furthermore, prior to the behavioral studies the animals had their food supply restricted to $85 \%$ of the daily intake to ensure their motivation for a food reward. In addition, they were not allowed any food for $24 \mathrm{~h}$ before behavioral testing. Access to water was always ad libitum. Six animals per group were used for behavioral testing, whilst morphological studies were performed by using the other six rats in each group (Figure 1).

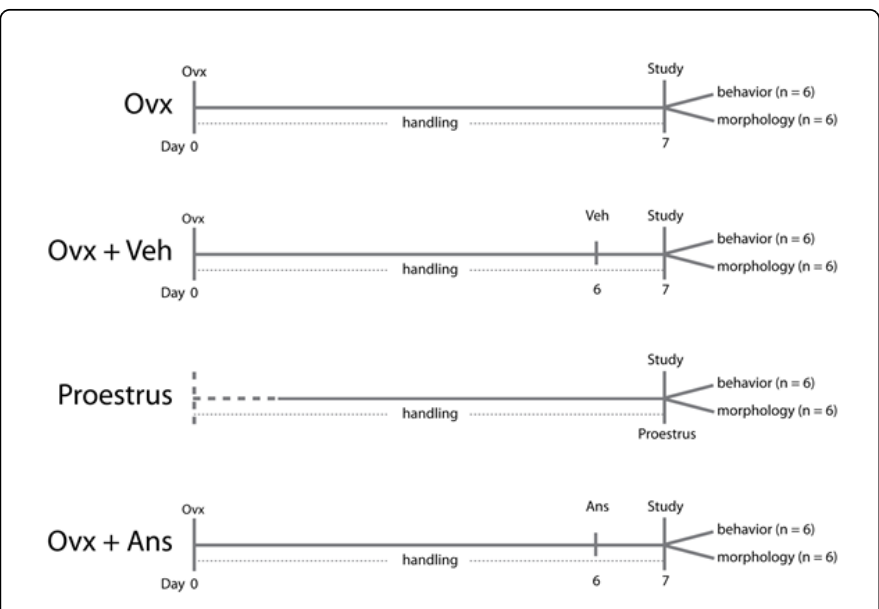

Figure 1: Diagram of the experimental design used in this study.

\section{Behavioral testing}

The six animals from each of the study groups were challenged to resolve an allocentric working memory paradigm in a white, opaque acrylic "Y" maze that was situated in an illuminated room with differential visuo-spatial signals. Each of the three arms of the maze could be closed with a sliding door, which were used in function of the test's needs. At the end of the adjacent arms of the $\mathrm{Y}$, a food well below floor level contained cereal as a reward.

Before starting of the behavioral test, the animals were habituated to the maze by allowing them to explore the three arms of the maze freely for ten minutes. The rats were then withdrawn from the maze and immediately reintroduced into it, having placed several pieces of cereal on the floor of each of the three arms and within the wells. When the rat had eaten all the cereal or after a further ten minutes, the animal was returned to its home cage. Twelve trials were then carried out according to a delayed match-to-sample procedure in a single one-day session.

In each trial the rat was introduced into the $\mathrm{Y}$ maze, and a study phase was then followed by a delay period and a test phase. The rat was placed in the vertical arm of the $\mathrm{Y}$ maze for thirty seconds (introduction) before the starting arm was opened, and it was only allowed to enter the open arm and eat the cereal from the well (study phase). It was then returned to the starting arm for a period of ten seconds (delay period) before the sliding door of the starting arm was opened again, allowing entry into both of the upper arms of the $\mathrm{Y}$ maze so that the rat could choose either. However, only the arm that was baited during the study phase contained the reward. If the rat turned to the same arm as in the study phase then a "correct response" was registered in the trial (test phase: Figure 2). Each trial was separated by a thirty-second delay (interval period). To avoid egocentric tendencies in the resolution of the trials, a random design was used such that the rat had to turn to the right in six trials and it had to turn to the left in the other six trials.

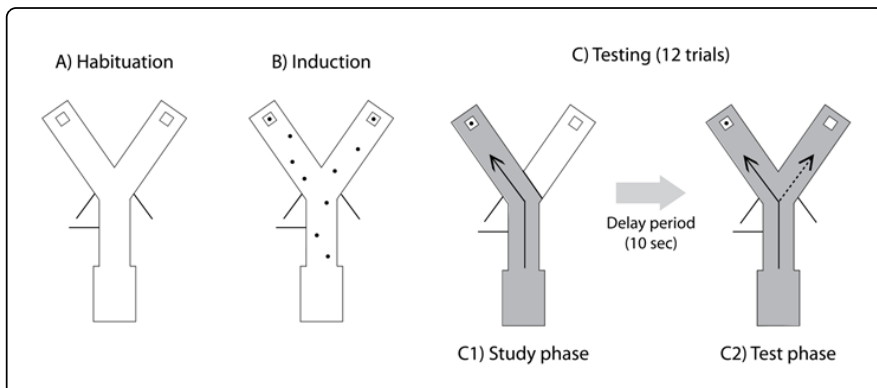

Figure 2: Experimental paradigm designed to evaluate allocentric working memory.

\section{Morphological studies}

Rats from each group were anesthetized with ketamine $(30 \mathrm{mg} / \mathrm{kg}$, i.m.) and sodium pentobarbital $(50 \mathrm{mg} / \mathrm{kg}$, i.p.), and they were then perfused with $200 \mathrm{ml}$ of a phosphate-buffered solution ( $\mathrm{pH} 7.4,0.01$ $\mathrm{M})$ containing sodium heparin (1000 IU/l) as an anticoagulant and procaine hydrochloride $(1 \mathrm{~g} / \mathrm{l})$ as a vasodilator [33]. The rats were then perfused with $200 \mathrm{ml}$ of a phosphate-buffered $4 \%$ formaldehyde fixative solution. Both solutions were perfused at a rate of $11.5 \mathrm{ml} / \mathrm{min}$. The rat's brain was then removed and maintained for at least $48 \mathrm{~h}$ in $100 \mathrm{ml}$ of fresh fixative solution. The bilateral blocks of prefrontal tissue were subsequently dissected out according to plates 7-11 of a brain atlas [34] and they were impregnated using a modified version of the Golgi technique [35]. Coronal slices (75 $\mu \mathrm{m}$ thick) were mounted on one slide per animal, and six third-layer pyramidal neurons of the pre-limbic/infralimbic prefrontal cortex from each of the six rats in 
Citation: Velázquez-Zamora DA, Martínez-Torres NI, Cervantes M, González-Burgos I (2016) Administration of Anastrozole to Ovariectomized Rats Impairs Working Memory in Association with Plastic Changes to Dendritic Spines on Prefrontal Third-layer Pyramidal Neurons. J Steroids Horm Sci 7: 179. doi:10.4172/2157-7536.1000179

Page 3 of 7

every group were analyzed. Pyramidal neurons were selected for spine counting based on three morphological criteria: (a) neurons had to be well impregnated; (b) neurons in which the bodies or branches selected for counting were obstructed by blood vessels, glia or heavy clusters of dendrites from neighboring impregnated cells were excluded; and (c) the apical arborization had to be fully impregnated and mainly intact. The dendritic spines were counted along a $50 \mu \mathrm{m}$ segment on each neuron in the middle section of a secondary dendrite protruding from the apical one (Figure 3, left panel). Sampling of the dendritic spines followed three morphological criteria: (a) belonging to a clearly distinguishable neuron found in layer three of the prefrontal cortex; (b) located on a secondary dendrite protruding from the middle third of the apical dendrite; (c) the dendritic segment selected for counting had to be in a homogenous plane of focus.

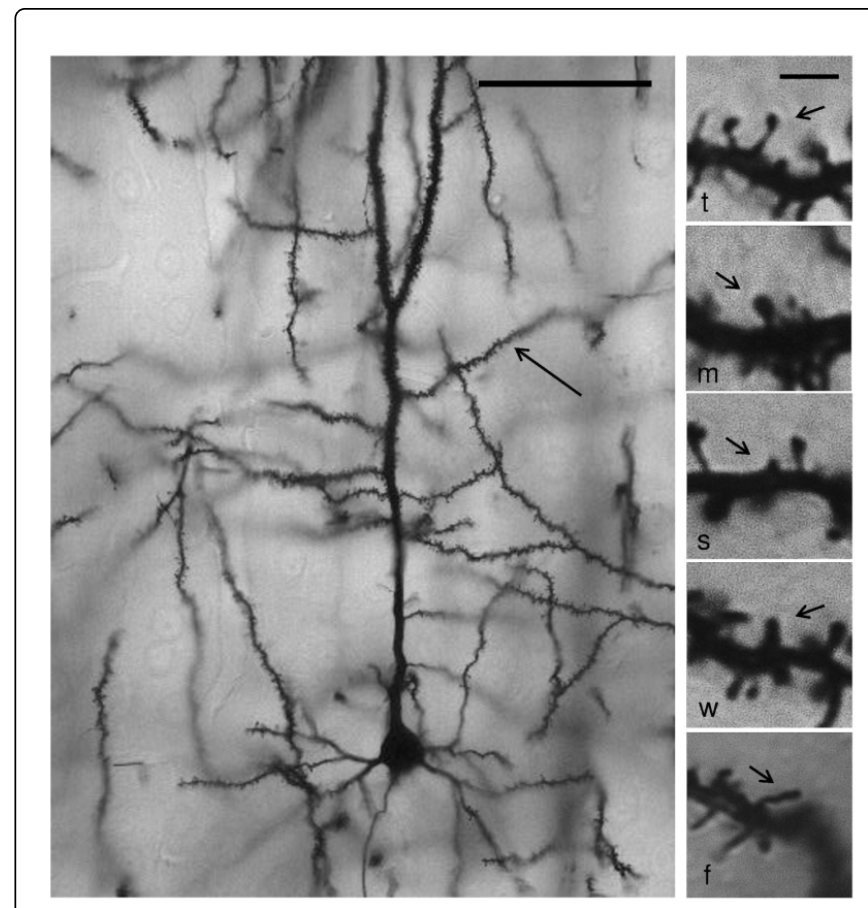

Figure 3: Left panel: photomicrograph of a representative layer III pyramidal neuron from the prelimbic/infralimbic prefrontal cortex, showing a secondary dendrite (arrow) from where the spines were counted. Scale bar $=100 \mu \mathrm{m}$. Right panel: photomicrographs of thin $(\mathrm{t})$, stubby $(\mathrm{s})$, mushroom $(\mathrm{m})$ and wide $(\mathrm{w})$ spines (arrows), such as those counted in this study. Scale bar $=2 \mu \mathrm{m}$.

A reliability index was determined for dendritic spine counting in an initial double-blind study: number of agreements-number of disagreements/number of agreements. Once a minimum reliability of 0.95 was reached, dendritic spines from each of the groups were quantified using a "blind" procedure. The density and proportion of thin, mushroom, stubby and wide spines were determined according to previously established criteria [36-38]: thin spines were defined as those in which the neck diameter was less than the total spine length and the head diameter was only slightly greater than the neck diameter; stubby spines were defined as those in which the neck diameter was more than or equal to the spine length; mushroom spines were defined as those in which both the diameter and length of the neck was much smaller than the head diameter, and the neck was shorter than that of thin spines; wide spines, which closely resemble stubby spines, were defined as those in which the total spine length was longer than the neck diameter (Figure 3, right panel). Spine counting was performed at 2,000X using a magnification changer in a light microscope coupled to an image analyzer (LAS 4.0).

\section{Statistics}

Behavioral data and spine density were analyzed by one-way ANOVA followed by the Tukey post hoc test, and the relative proportional density of each spine type was analyzed using one-way ANOVA followed by Bonferroni correction post hoc test.

\section{Ethical considerations}

All experimental procedures were designed to minimize the pain and discomfort of the experimental animals. The experimental protocol was approved by the Committee for Research Ethics of the Instituto Mexicano del Seguro Social (Mexico), and the experimental procedures were performed according to the $\mathrm{NIH}$ guidelines for the Care and Use of Laboratory Animals (NIH Publications No. 80-23, 1996 revision).

\section{Results}

\section{Allocentric working memory}

The behavioral evaluation of allocentric working memory reflected significant variation between the four groups of animals studied $(\mathrm{F}=27.546, \mathrm{p}<0.0001)$. The number of correct responses by the Proestrus rats in the $\mathrm{Y}$ maze was more than those recorded by the Ovx $(\mathrm{p}<0.0001)$, Ovx + Veh $(\mathrm{p}<0.0001)$ and $\mathrm{Ovx}+$ Ans $(\mathrm{p}<0.0001)$ animals. In addition, the $\mathrm{Ovx}+\mathrm{Ans}$ rats made fewer correct responses than both the Ovx $(\mathrm{p}<0.01)$ and Ovx+Veh $(\mathrm{p}<0.008)$ animals. As expected, no significant differences were observed between the Ovx and Ovx+Veh groups (Figure 4).

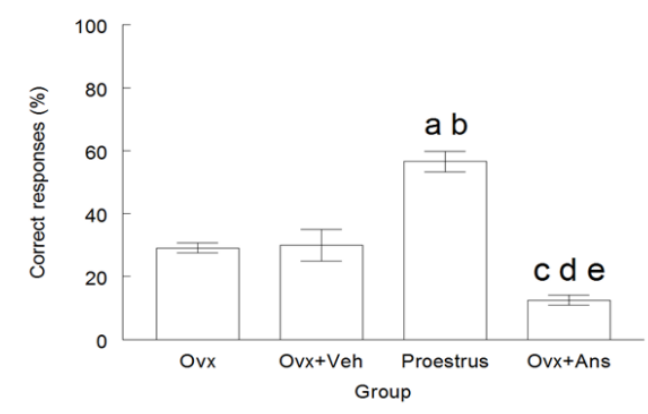

Figure 4: Percentage of the correct responses in the $\mathrm{Y}$ maze by ovariectomized rats $(\mathrm{Ovx})$, ovariectomized rats administered the vehicle alone $(\mathrm{Ovx}+\mathrm{Veh})$, rats in proestrus (Proestrus) and ovariectomized rats administered Anastrozole (Ovx+Ans). The data are represented as the mean \pm SEM: a, Vs. Ovx; b, Vs. Ovx+Veh; c, $V s$. Ovx; d, Vs. Ovx+Veh; e, Vs. Proestrus.

\section{Spine density}

When the dendritic spine density was analyzed, significant differences were found between the groups studied ( $F=16.893$, 
Citation: Velázquez-Zamora DA, Martínez-Torres NI, Cervantes M, González-Burgos I (2016) Administration of Anastrozole to Ovariectomized Rats Impairs Working Memory in Association with Plastic Changes to Dendritic Spines on Prefrontal Third-layer Pyramidal Neurons. J Steroids Horm Sci 7: 179. doi:10.4172/2157-7536.1000179

Page 4 of 7

$\mathrm{p}<0.0001)$. Pyramidal neurons from layer III of the prefrontal cortex of Proestrus rats had a greater density of dendritic spines than Ovx $(\mathrm{p}<0.0001), \quad \mathrm{Ovx}+$ Veh $(\mathrm{p}<0.0001)$ and $\mathrm{Ovx}+$ Ans rats $(\mathrm{p}<0.04)$. Similarly, there was a greater density of spines on neurons from Ovx + Ans animals than on those from the Ovx $(\mathrm{p}<0.01)$ and $\mathrm{Ovx}+\mathrm{Veh}$ $(\mathrm{p}<0.04)$ groups. Again, there was no difference in spine density between the Ovx and Ovx+Veh rats (Figure 5).

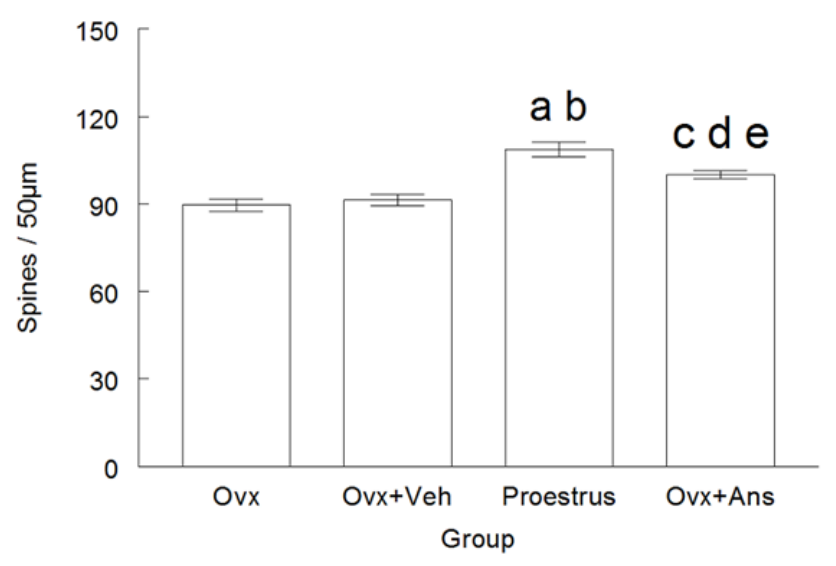

Figure 5: Density of dendritic spines on pyramidal neurons in the prelimbic/infralimbic prefrontal cortex of ovariectomized rats $(\mathrm{Ovx})$, ovariectomized rats administered the vehicle alone (Ovx + Veh), rats in proestrus (Proestrus) and ovariectomized rats administered Anastrozole (Ovx+Ans). The data are represented as the mean \pm SEM: A, Vs. Ovx; b, Vs. Ovx+Veh; c, Vs. Ovx; d, Vs. Ovx+Veh; e, Vs. Proestrus.

\section{Spine types}

The proportion of thin spines $(\mathrm{F}=4.632, \mathrm{p}<0.01)$, mushroom spines $(\mathrm{F}=12.989, \mathrm{p}<0.0001)$ and filopodia $(\mathrm{F}=66.042, \mathrm{p}<0.0001)$ varied between the distinct experimental groups of rats. The density of thin spines was greater in the Proestrus rats than in both the $\mathrm{Ovx}(\mathrm{p}<0.03)$ and $\mathrm{Ov}+\mathrm{Ans}(\mathrm{p}<0.02)$ groups, while there were no statistical differences between the Ovx, Ovx+Veh and Ovx+Ans rats. Similarly, a higher density of mushroom spines was evident in the Proestrus group when compared to the Ovx $(\mathrm{p}<0.0001)$, Ovx + Veh $(\mathrm{p}<0.0001)$ and $\mathrm{Ovx}$ + Ans rats $(\mathrm{p}<0.001)$ and again, there were no differences in the density of mushroom spines between the Ovx, Ovx+Veh and Ovx+Ans groups. The proportions of stubby and wide spines did not vary significantly between the four groups studied. By contrast, there was a significantly higher proportion of filopodial structures in the Ovx + Ans animals than in the three other control groups: the $\mathrm{Ovx}(\mathrm{p}<0.0001)$, Ovx + Veh $(\mathrm{p}<0.0001)$ and Proestrus animals $(\mathrm{p}<0.0001$ : Table 1$)$.

\begin{tabular}{|l|l|l|l|l|}
\hline Spine type & Ovx & Ovx+Veh & Proestrus & Ovx+Ans \\
\hline Thin & $36.9 \pm 1.8$ & $37.8 \pm 0.6$ & $44.5 \pm 1.4^{\mathrm{a}}$ & $38.8 \pm 2.4^{\mathrm{c}}$ \\
\hline Mushroom & $26.1 \pm 0.7$ & $26.1 \pm 1.8$ & $33.0 \pm 1.1^{\mathrm{ab}}$ & $28.2 \pm 0.8^{\mathrm{c}}$ \\
\hline Stubby & $22.2 \pm 0.7$ & $20.4 \pm 1.0$ & $24.0 \pm 1.2$ & $24.5 \pm 0.4$ \\
\hline Wide & $6.4 \pm 1.1$ & $5.3 \pm 0.4$ & $5.3 \pm 0.3$ & $6.2 \pm 0.2$ \\
\hline
\end{tabular}

\begin{tabular}{|l|l|l|l|l|}
\hline Filopodia & $1.0 \pm 0.2$ & $0.2 \pm 0.09$ & $0.8 \pm 0.2$ & $5.9 \pm 0.5 \mathrm{abc}$ \\
\hline
\end{tabular} $\begin{aligned} & \text { Mean } \pm \text { SEM; ANOVA, Bonferroni; } p<0.05 \text {; a: vs. Ovx; b: vs. Ovx+Veh; c: vs. } \\
& \text { Proestrus }\end{aligned}$

Table 1: Density of the different spine types counted in pyramidal neurons from the layer III of the prefrontal cortex of female rats.

\section{Discussion}

Clinical [39,40] and experimental [23,41] studies have demonstrated an important regulatory role of estradiol on the morphological and functional characteristics of the neural substrate in the prefrontal cortex involved in the expression of verbal and spatial working memory [42,43]. In particular, the inhibition of estradiol synthesis dampens the ability to solve spatial working memory tests. Such an effect can be produced by interfering with testosterone aromatase activity, a phenomenon observed in women that receive anastrozole as a part of breast cancer therapy $[28,44,45]$.

Anastrozole, as well as letrozole, are nonsteroidal testosterone aromatase inhibitors that bind reversibly to the aromatase enzyme, impeding the synthesis of estradiol otherwise resulting from testosterone aromatization [46,47]. Thus, besides breast cancer therapy, anastrozole has also been used as a clinical pharmacological approach aimed to counteract, trough testosterone aromatase inhibition, other phathophysiological conditions in human beings, such as lowtestosterone hypogonadism in elderly men [48]. In addition, anastrozole treatment has resulted in an experimental model of brainsyntetized estrogen insufficiency for different, in vitro $[49,50]$ and in vivo [51-53], experimental designs.

On the other hand, changes in plasma estradiol levels during the estrus cycles may affect certain characteristics of learning and working memory [54,55] brain processes that require the processing and updating of information to produce short-term memory responses $[56,57]$. It is well known that peripheral plasma levels of estradiol, resulting from cyclic ovary steroid synthesis and secretion vary from basal values (less than $10 \mathrm{pg} / \mathrm{ml}$ ) during estrus, and progressively increase trough metaestrus and diestrus to achieve their maximal values on late proestrus (near around $40 \mathrm{pg} / \mathrm{ml}$ ) [58]. When plasma levels of estradiol are higher, the performance of female rats in resolving spatial working memory tests is preferentially based on allocentric strategies rather than egocentric strategies [59], a result of a switching activity in the prefrontal cortex that foments either allocentric or egocentric performance [60].

Moreover, estradiol therapy improves the deficient performance of ovariectomized rats in prefrontal cortex dependent allocentric working memory tests, as well as eliciting plastic changes and an increase in dendritic spine density, mainly due to the higher proportion of thin dendritic spines in layer III pyramidal neurons of the prefrontal cortex $[61,62]$. These neurons are involved in determining whether allocentric or egocentric strategies are employed to solve working memory tests, as well as in processing the sensory/motor memory information required for the memory fields to adopt the adequate working memory strategy [63-65] Here, ovariectomized rats resolved the working memory task inefficiently and they did so at a probabilistic level of chance $(50 \%)$. However, ovariectomized rats that received anastrozole performed below $50 \%$ efficiency and they were even less efficient than the control ovariectomized rats. These findings of significantly fewer correct responses when ovariectomized rats received anastrozole in the allocentric spatial working memory test, suggests that the estradiol 
Citation: Velázquez-Zamora DA, Martínez-Torres NI, Cervantes M, González-Burgos I (2016) Administration of Anastrozole to Ovariectomized Rats Impairs Working Memory in Association with Plastic Changes to Dendritic Spines on Prefrontal Third-layer Pyramidal Neurons. J Steroids Horm Sci 7: 179. doi:10.4172/2157-7536.1000179

Page 5 of 7

synthesized in brain structures, including the prefrontal cortex, may fulfill a relevant role in the neural substrates involved in cognitive functions. Indeed, estrogenic activity has been proposed to affect synaptic plasticity and the proportions of dendritic spines, thereby influencing cognitive performance. Such a phenomenon may be particularly relevant if driven by estradiol synthesized locally in specific brain structures rather than being supplied from that synthesized in the ovary $[24,66]$.

There is evidence that the plasticity of dendritic spine synapses driven by the estrogen produced through brain aromatase activity may have different functional characteristics depending on the specific brain structures where they were synthetized, in female rats $[19,67,68]$. In addition, the effects of aromatase inhibition on dendritic spine plasticity may change in different experimental conditions. Thus, while inhibiting aromatase with letrozole in cycling rats did not affect synaptic spine density on prefrontal cortex pyramidal neurons such treatment did significantly reduce the number of dendritic spinemediated synapses. Moreover, aromatase inhibition down-regulated synaptophysin and spinophilin expression in the hippocampus of both cycling and ovariectomized rats [30], and in hippocampal cell cultures [68].

In the present work, dendritic spine density on layer III pyramidal neurons in the prefrontal cortex increased significantly as a result of anastrozole-induced inhibition of brain aromatase activity in the absence of a gonadal source of estrogen in the brain. This increase was associated with a higher proportion of filopodia. According to earlier pioneering studies [69], increased dendritic spine density would lead to better synaptic efficiency. Thus, the higher proportion of filopodia may reflect the initial steps of neuronal activation and the development of neural processes during de novo dendritic spine formation [70-73]. However, recent studies suggested that although mature spines could develop from filopodial structures in adult rodents, these might be inactive [74]. The formation of inactive spines would be consistent with our findings, as despite the increase in dendritic spine density in ovariectomized females that received anastrozole, they performed worse in the working memory task. Thus, while the increase in dendritic spines observed would suggests a compensatory response, our behavioral findings show that these morphological changes seem not to provoke functional compensation on neural substrates in the prefrontal cortex when the modulatory activity of estradiol is absent.

Thin spines have been associated with learning capabilities whilst mushroom spines have been related with memory storage $[75,76]$. Synaptic stimulation through both stubby and wide spines has been suggested to regulate neuron excitability $[36,77]$. It is noteworthy that the proportional density of any spine type was unaltered by anastrozole administration to the ovariectomized animals. This is particularly relevant given the increase in dendritic spine density and the enhanced working memory impairment. On the one hand, the homogenous increase in spine types would account for the "stable" postsynaptic translation of synaptic information and on the other hand, the nonpredominance of a specific type of spine suggests that the lack of E2 has a homogeneous impact on spine dynamics.

Thus, neural processes appear to be altered by the loss of the estrogenic activity resulting from estradiol synthesis by the neural substrates in the prefrontal cortex that drives cognitive activity, a phenomenon that merits further research.

\section{Funding statement}

This work received support from the Coordinación de la Investigación Científica, Universidad Michoacana de San Nicolás de Hidalgo (Reg. 108907).

\section{References}

1. McEwen BS, Milner TA (2007) Hippocampal formation: Shedding light on the influence of sex and stress on the brain. Brain Res Rev 55: 343-355.

2. McEwen BS, Akama KT, Spencer-Segal JL, MilnervTA, Waters EM (2012) Estrogen effects on the brain: actions beyond the hypothalamus via novel mechanisms. Behav Neurosci 126: 4-16.

3. Sharma K, Mehra RD (2008) Long-term administration of estrogen or tamoxifen to ovariectomized rats affords neuroprotection to hippocampal neurons by modulating the expression of Bcl-2 and Bax. Brain Res 1204: $1-15$.

4. Xu X, Zhang Z (2006) Effects of estradiol benzoate on learning-memory behavior and synaptic structure in ovariectomized mice. Life Sci 79: 1553-1560.

5. Compagnone NA, Mellon SH (2000) Neurosteroids: biosynthesis and function of these novel neuromodulators. Front Neuroendocrinol 21: $1-56$.

6. Shibuya K, Takata N, Hojo Y, Furukawa A, Yasumatsu N, et al. (2003) Hippocampal cytochrome P450s synthesize brain neurosteroids which are paracrine neuromodulators of synaptic signal transduction. Biochem Biophys Acta 1619: 301-316.

7. Do-Rego JL, Seong JY, Burel D, Leprince J, Luu-The V, et al. (2009) Neurosteroid biosynthesis: enzymatic pathways and neuroendocrine regulation by neurotransmitters and neuropeptides. Front Neuroendocrinol 30: 259-301.

8. Mellon SH, Vaudry H (2001) Biosynthesis of neurosteroids and regulation of their synthesis. Int Rev Neurobiol 46: 33-78.

9. Pelletier G (2010) Steroidogenic enzymes in the brain: morphological aspects. Prog Brain Res 181: 193-207.

10. Plassart-Schiess E, Baulieu EE (2001) Neurosteroids: recent findings. Brain Res Rev 37: 133-140.

11. Stoffel-Wagner B (2001) Neurosteroid metabolism in the human brain Eur J Endocrinol 145: 669-679.

12. Tabatadze N, Sato SM, Woolley CS (2014) Quantitative Analysis of LongForm Aromatase mRNA in the Male and Female Rat Brain. Plos One 9: 1-9.

13. Barker JM, Galea LAM (2009) Sex and regional differences in estradiol content in the prefrontal cortex, amygdala and hippocampus of adult male and female rats. Gen Comp Endocrinol 164: 77-84.

14. Hojo Y, Hattori TA, Enami T, Furukawa A, Suzuki K, et al. (2004) Adult male rat hippocampus synthesizes estradiol from pregnenolone by cytochromes P45017alpha and P450 aromatase localized in neurons. Proc Natl Acad Sci 101: 865-870.

15. Roselli CE, Abdelgadir SE, Ronnekleiv OK, Klosterman SA (1998) Anatomic distribution and regulation of aromatase gene expression in the rat brain. Biol Reprod 58: 79-87.

16. Wei J, Yuen EY, Liu W, Li X, Zhong P, et al. (2014) Estrogen protects against the detrimental effects of repeated stress on glutamatergic transmission and cognition. Mol Psychiatry 19: 588-598.

17. Arevalo MA, Azcoitia I, Gonzalez-Burgos I, Garcia-Segura LM (2015) Signaling mechanisms mediating the regulation of synaptic plasticity and memory by estradiol. Horm Behav 74: 19-27.

18. Velázquez-Zamora DA, González-Tapia D, González-Ramírez MM, Flores-Soto ME, Vázquez-Valls E, et al. (2012) Plastic changes in dendritic spines of hippocampal CA1 pyramidal neurons from ovariectomized rats after estradiol treatment. Brain Res 1470: 1-10.

19. Vierk R, Brandt N, Rune GM (2014) Hippocampal estradiol synthesis and its significance for hippocampal synaptic stability in male and female animals. Neuroscience 22: 24-32. 
Citation: Velázquez-Zamora DA, Martínez-Torres NI, Cervantes M, González-Burgos I (2016) Administration of Anastrozole to Ovariectomized Rats Impairs Working Memory in Association with Plastic Changes to Dendritic Spines on Prefrontal Third-layer Pyramidal Neurons. J Steroids Horm Sci 7: 179. doi:10.4172/2157-7536.1000179

Page 6 of 7

20. Vierk R, Bayer J, Freitag S, Muhia M, Kutsche T, et al. (2015) Structurefunction-behavior relationship in estrogen-induced synaptic plasticity. Horm Behav 74: 139-148.

21. Frankfurt M, Luine V (2015) The evolving role of dendritic spines and memory: Interaction(s) with estradiol. Horm Behav 74: 28-36.

22. Velázquez-Zamora DA, González-Tapia D, Feria-Velasco A, GonzálezBurgos I (2014) Estrogenic modulation of memory-associated neuroplasticity. In: González-Burgos I Editor. Estrogens and cognition. Psychobiological and clinical aspects. Research Signpost 1-23.

23. Bayer J, Rune G, Schultz H, Tobia MJ, Mebes I, et al. (2015) The effect of estrogen synthesis inhibition on hippocampal memory. Psychoneuroendocrinology 56: 213-225.

24. Bian C, Zhu H, Zhao Y, Cai W, Zhang J (2014) Intriguing roles of hippocampus-synthesized $17 \beta$-estradiol in the modulation of hippocampal synaptic plasticity. J Mol Neurosci 54: 271-281.

25. Galvin C, Ninan I (2014) Regulation of the mouse medial prefrontal cortical synapses by endogenous estradiol. Neuropsychopharmacology 39: 2086-2094.

26. Garcia-Segura LM (2008) Aromatase in the brain: not just for reproduction anymore. J Neuroendocrinol 20: 705-712.

27. Hojo Y, Murakami G, Mukai H, Higo S, Hatanaka Y, et al. (2008) Estrogen synthesis in the brain-Role in synaptic plasticity and memory. Mol Cell Endocrinol 290: 31-43.

28. Phillips KA, Ribi K, Fisher R (2011) Do aromatase inhibitors have adverse effects on cognitive function? Breast Cancer Res 13: 1-7.

29. Rune GM, Frostcher M (2005) Neurosteroid synthesis in the hippocampus: role in synaptic plasticity. Neuroscience 136: 833-842.

30. Zhou L, Fester L, von Blittersdorff B, Hassu B, Nogens H, et al. (2010) Aromatase inhibitors induce spine synapse loss in the hippocampus of ovariectomized mice. Endocrinology 151: 1153-1160.

31. Buzdar AU, Robertson JF, Eiermann W, Nabholtz JM (2002) An overview of the pharmacology and pharmacokinetics of the newer generation aromatase inhibitors anastrozole, letrozole, and exemestane Cancer 95: 2006-2016.

32. Sanford M, Plosker GL (2008) Anastrozole: a review of its use in postmenopausal women with early-stage breast cancer. Drugs 68: 1319-1340.

33. Feria-Velasco A, Karnovsky MJ, (1970) Optimal central nervous system preservation with glutaraldehyde perfusion for ultrastructural study. Arch Invest Med 1: 201-220.

34. Paxinos G, Watson C (1986) The rat brain in stereotaxic coordinates $\left(2^{\text {nd }}\right.$ edn.), Academic Press.

35. González-Burgos I, Tapia-Arizmendi G, Feria-Velasco A (1992) Golgi method without osmium tetroxide for the study of the central nervous system. Biotech Histochem 67: 288-296.

36. González-Burgos I (2009) Dendritic spines plasticity and learning/ memory processes: Theory, evidence and perspectives. In: Baylog LR Editor. Dendritic spines. Biochemistry, modelling and properties. Nova Science Publishers pp: 163-186.

37. González-Burgos I (2012) From synaptic transmission to cognition: an intermediary role for dendritic spines. Brain Cogn 80: 177-183.

38. Harris KM, Jensen FE, Tsao BH (1989) Ultraestructure, development and plasticity of dendritic spine synapses in area CA1 of the rat hippocampus: extending our vision with serial electron microscopy and threedimensional analyses. In: Chan-Palay $\mathrm{V}$ and Kôhler $\mathrm{CH}$ Editors. The Hippocampus, New Vistas pp: 33-52.

39. Berent-Spillson A, Persad CC, Love T, Sowers M, Randolph JF, et al. (2012) Hormonal environment affects cognition independent of age during the menopause transition. J Clin Endocrinol Metab 97: 1686-1694.

40. Hampson E, Morley EE (2013) Estradiol concentrations and working memory performance in women of reproductive age. Psychoneuroendocrinology 38: 2897-2904.

41. Hara Y, Yuk F, Puri R, Janssen WG, Rapp PR, et al. (2014) Presynaptic mitochondrial morphology in monkey prefrontal cortex correlates with working memory and is improved with estrogen treatment. Proc Natl Acad Sci 7: 486-491.

42. Dumitriu D, Rapp PR, McEwen BS, Morrison JH (2010) Estrogen and the aging brain: an elixir for the weary cortical network. Ann NY Acad Sci 1204: 104-112.

43. León-Domínguez U, Martín-Rodríguez JF, León-Carrión J (2015) Executive n-back tasks for the neuropsychological assessment of working memory. Behav Brain Res 292: 167-173.

44. Bender CM, Merriman JD, Gentry AL, Ahrendt GM, Berga SL, et al. (2015) Patterns of change in cognitive function with anastrozole therapy. Cancer 121: 2627-2636.

45. Shilling V, Jenkins V, Fallowfield L, Howell T (2003) The effects of hormone therapy on cognition in breast cancer. J Steroid Biochem Mol Biol 86: 405-412.

46. Aman U, Buzdar AU, John FR, Robertson JFR, Eiermann W, Nabholtz JM (2002) An overview of the pharmacology and pharmacokinetics of the newer generation aromatase inhibitors anastrozole, letrozole, and exemestane. Cancer 95: 2006-2016

47. Dukes M, Edwards PN, Large M, Smith IK, Boyle T (1996) The preclinical pharmacology of "Arimidex" (anastrozole: ZD1033)-a potent, selective aromatase inhibitor. J Steroid Biochem Mol Biol 58: 4796-4805.

48. Leder BZ (2007) Testosterone, estradiol and aromatase inhibitor therapy in elderly men. J Steroid Biochem Mol Biol 106: 162-167.

49. Chamniansawat S, Chongthammakun SA (2012) Priming role of local estrogen on exogenous estrogen-mediated synaptic plasticity and neuroprotection. Exp Mol Med 44: 403-411.

50. Liu M, Hurn PD, Roselli CE, Alkayed NJ (2007) Role of P450 aromatase in sex-specific astrocytic cell death. J Cereb Blood Flow Metab 27: 135-141.

51. Hodosy J, Celec P, Ostatníková D, Cagánová M, Putz Z, et al. (2009) The effect of anastrozol on spatial memory in adult rats. Cent Eur J Biol 4 186-189.

52. Moradpour F, Naghdi N, Fathollahi Y (2006) Anastrozole improved testosterone-induced impairment acquisition of spatial learning and memory in the hippocampal CA1 region in adult male rats. Behav Brain Res 175: 223-232.

53. Turner KJ, Morley M, Atanassova N, Swantson D, Sharpe RM (2000) Effect of chronic administration of an aromatase inhibitor to adult male rats on pituitary and testicular function and fertility. J Endocrinol 164: 225-238.

54. Hussain D, Hoehne A, Woodside B, Brake WG (2013) Reproductive experience modifies the effects of estradiol on learning and memory bias in female rats. Horm Behav 63: 418-423.

55. Korol DL (2004) Role of estrogen in balancing contributions from multiple memory systems. Neurobiol Learn Mem 82: 309-323.

56. Fuster JM (1999) Synopsis of function and dysfunction of the frontal lobe. Acta Psychiatr Scand Suppl 395: 51-57.

57. Baddeley A (2003) Working memory: looking back and looking forward. Nat Rev Neurosci 4: 829-839.

58. Freeman ME (2006) Neuroendocrine control of ovarian cycle of the rat In: Neill JD Editor. Knobil and Neill's Physiology of Reproduction Vol 2, Chapter 43, (3 $3^{\text {rd }}$ edn.), Elsevier, pp 2327-2388.

59. Korol DL, Kolo LL (2002) Estrogen-induced changes in place and response learning in young adult female rats. Behav Neurosci 116: 411-420.

60. White NM, McDonald RJ (2002) Multiple parallel memory systems in the brain of the rat. Neurobiol Learn Mem 77: 125-184.

61. Khan MM, Dhandapani KM, Zhang QG, Brann DW (2013) Estrogen regulation of spine density and excitatory synapses in rat prefrontal and somatosensory cerebral cortex. Steroids 78: 614-623.

62. Velázquez-Zamora DA, García-Segura LM, González-Burgos I (2012) Effects of selective estrogen receptor modulators on allocentric working memory performance and on dendritic spines in medial prefrontal cortex pyramidal neurons of ovariectomized rats. Horm Behav 61: 512-517. 
Citation: Velázquez-Zamora DA, Martínez-Torres NI, Cervantes M, González-Burgos I (2016) Administration of Anastrozole to Ovariectomized Rats Impairs Working Memory in Association with Plastic Changes to Dendritic Spines on Prefrontal Third-layer Pyramidal Neurons. J Steroids Horm Sci 7: 179. doi:10.4172/2157-7536.1000179

Page 7 of 7

63. Fuster JM (1997) The prefrontal cortex: Anatomy, physiology, and neuropsychology of the frontal lobe. ( $3^{\text {rd }}$ edn.), Lippincott-Raven.

64. Goldman-Rakic PS (1999) The "Psychic" neuron of the cerebral cortex. Ann N Y Acad Sci 868: 13-26.

65. Rich EL, Shapiro M (2009) Rat prefrontal cortical neurons selectively code strategy switches. J Neurosci 29: 7208-7219.

66. González-Flores O, Domínguez-Ordóñez R, González-Burgos I (2015) The celular and molecular mechanisms driving the estrogenic modulation of synaptic activity in mnemonic information processing Synaptic fundamentals in memory performance. Nova Science Publishers.

67. Kato A, Hojo Y, Higo S, Komatsuzaki Y, Murakami G, et al. (2013) Female hippocampal estrogens have a significant correlation with cyclic fluctuation of hippocampal spines. Front Neu Cir 18: 149.

68. Kretz O, Fester L, Wehrenberg U, Zhou L, Brauckmann S, et al. (2004) Hippocampal synapses depend on hippocampal estrogen synthesis. J Neurosci 24: 5913-5921.

69. Harris KM, Kater SB (1994) Dendritic spines: cellular specializations imparting both stability and flexibility to synaptic function. Ann Rev Neurosci 17: 341-371.

70. Chen CC, Bajnath A, Brumberg JC (2015) The impact of development and sensory deprivation on dendritic protrusions in the mouse barrel cortex. Cereb Cortex 25: 1638-1653.
71. Harris KM (1999) Structure, development, and plasticity of dendritic spines. Curr Opin Neurobiol 9: 343-348.

72. Velázquez-Zamora DA, Martínez-Degollado M, González-Burgos I (2011) Morphological development of dendritic spines on rat cerebellar Purkinje cells. Int J Dev Neurosci 29: 515-520.

73. Yuste $\mathrm{R}(2010)$ Dendritic spines. ( $1^{\text {st }}$ edn.), The MIT Press.

74. Caffino L, Giannotti G, Malpighi C, Racagni G, Fumagalli F (2015) Shortterm withdrawal from developmental exposure to cocaine activates the glucocorticoid receptor and alters spine dynamics. Eur Neuropsychopharmacology 25: 1832-1841.

75. Kasai H, Matsuzaki M, Noguchi J, Yasumatsu N, Nakahara H (2003) Structure-stability-function relationships of dendritic spines. Trends Neurosci 26: 360-368.

76. Matsuzaki M, Honkura N, Ellis-Davies GCR, Kasai H (2004) Structural basis of long-term potentiation in single dendritic spines. Nature 429: 761-766.

77. Harris KM, Jensen FE, Tsao B (1992) Three-dimensional structure of dendritic spines and synapses in rat hippocampus (CA1) at postnatal day 15 and adult ages: implications for the maturation of synaptic physiology and long-term potentiation. J Neurosci 12: 2685-2705. 